FAMILIAL PRESENILE DEMENTIA

\title{
REPORT OF CASE WITH CLINICAL AND PATHOLOGICAL FEATURES OF ALZHEIMER'S DISEASE
}

\author{
BY
}

\section{W. H. MCMENEMEY, C. WORSTER-DROUGHT, J. FLIND and H. G. WILLIAMS}

From the Napsbury Hospital Laboratories and the Laboratory of the Department of Surgery, University of Oxford

(RECEIVEd 17TH MaRCH, 1939)

\begin{abstract}
Although it has been suggested that Alzheimer's disease is not uncommon (Malamud and Lowenberg, 1929 ; Mayer-Gross, 1938), cases which show a family history of presenile dementia are distinctly rare. Lowenberg and Waggoner (1934) have described such an example coming under observation at the age of 32, and reference was made in a discussion on presenile dementia between the sections of Neurology and Psychiatry of the Royal Society of Medicine in 1933 to "data suggestive of senile and presenile types of dementia in the direct ancestry of a number of patients" (Gillespie et al., 1933). Lowenberg has also noted the occurrence of senile dementia in a father and Alzheimer's disease in the son.

In discussing the literature of familial and hereditary Alzheimer's disease, Lowenberg and Waggoner refer to a probable example in a father and daughter recorded by Schottky and to its occurrence in twins as reported by Braunmühl.

The present case is recorded as showing a family history of presenile dementia and a typical clinical course with histo-pathological findings of the disease which bears Alzheimer's name.
\end{abstract}

\section{Case Record}

L. T. J. E., a male aged 51 years, was admitted to hospital on 21 st October, 1935 , on account of mental deterioration and stiffness of the limbs. The following history was obtained from his wife. He was employed as a clerk in a Metropolitan Gas Company, where, being exceptionally good at figures, he held a post of considerable responsibility in the Accountant's Department. At the outbreak of the Great War he was given a similar post at Woolwich with the rank of major, and, his work having been of a consistently high standard, he was rewarded with a decoration. After the war he first returned to his former occupation, but soon ventured into a partnership with a friend in a motor engineering concern in which he took charge of the office and secretarial department. The business flourished and he had no reason to regret the change. 
The present illness appears to have dated from 1929 or 1930 , when the patient was 46 years of age. The first feature to be noticed was a blunting of his usual enthusiasm for various activities and a lack of interest in his ordinary pursuits. As he was assisted in his work by an efficient clerk whom he had himself trained, any falling away in his management of the business was, at first, not noticed. Towards the end of 1930 his friends were making allowances for his gross mistakes at bridge, a game at which he had formerly shown considerable skill. During the following years mental deterioration progressed, especially during the six months prior to his admission to hospital, so that a nurse had to be employed to help in his management. A year before his coming to hospital, however, he was still able, unaccompanied, to meet a friend at the railway station, but was not at this time displaying any interest in everyday occurrences.

His wife finds difficulty in estimating the time of appearance of the stiffness in his limbs. There is no doubt that immediately preceding the onset of mental failure he was playing a good game of tennis, and the earliest signs of loss of interest were accompanied by rapid and undue fatigability at this game. About a year later he noticed on holiday that he was finding it difficult to climb stiles. His movements gradually and progressively became less easily performed.

Mental State on Admission.-The most striking defect was in the intellectual field. There was profuse memory disturbance affecting remote but more particularly recent events. He was disorientated for time and place and was unable to give any account of himself. In a general way he appreciated simple questions, but only after an interval of time, and frequently the question had to be repeated. He exhibited paraphasia and perseveration. If he attempted a sentence of more than about six words, an unintelligible jargon usually resulted. Sometimes he recognized the fact that he had used the wrong word and occasionally after an effort, he was able to correct his mistake ; for example, when asked his name he replied, "Annie, Annie-no" (pause) "Louise"; when asked his occupation he replied " coke, coke" (pause) "clerk." He named the year of his birth correctly, but could not state his birthday beyond " 11 th11th-11th." He named correctly such objects as a key, pencil, watch, penny, and sixpence; a simple pocket-torch, however, he called (after much effort) a " microscope"; a halfpenny he described as "ten shilling-no-no-one tenth" ; a fountain pen elicited "fountain, fountain-something." With his eyes closed he was unable to identify by their shape, size, and consistency any of the objects named above. He could read aloud some of the headlines in newspapers and magazines correctly but slowly. At times he made simple calculations on paper accurately, but at others he made gross errors. $\mathrm{He}$ was unable to name the days of the week, the months of the year, or the letters of the alphabet. He was disinclined to write owing to the difficulty resulting from spasticity, but on one occasion, when requested, he determinedly started to write "Friday," but could not proceed beyond the first letter. He was co-operative, but tired easily and had to have frequent rests during the examinations.

Physical Condition.-He showed general spasticity of the limbs, the arms 
being held slightly flexed at the forearms and pronated; there was definite resistance to passive movements ; the legs were similarly spastic and slightly flexed at the knees. In walking, progression was slow, with short steps, the knees slightly bent and the back bowed. No Parkinsonian mask was present and the movements of the neck were moderately free.

The pupils were average in size, equal, and reacted normally; fundus oculi was natural. Facial movements were good; tongue was slightly tremulous. Speech was hesitant, slurred, and incoherent, with sentences incompleted. Arm reflexes were brisk and equal ; abdominal reflexes could not be elicited. Kneejerks were brisk and equal; ankle jerks were sluggish; plantar reflexes were indefinite, but mainly flexor. There was incontinence of urine and fæces. Sensation, as far as it was possible to judge, was intact, certainly as regards grosser forms. Cardio-vascular system was normal; blood pressure was 120/75. Arteries were in good condition. Urine-nil abnormal was detected.

Subsequent Progress.-There was little change in the main features of the patient's condition during the first few weeks. His mood consistently suggested that he was worried and anxious. Occasionally he made spontaneous remarks of quite surprising quality, such as, "I've got very slow, I know" ; and on another occasion, when he almost tripped in walking, "I am a clumsy fool." At times he was irritable and threw the nearest suitable article. His habits were degraded unless careful attention was given to him. There was nothing to suggest that he was experiencing hallucinations. He also exhibited shocklike contractions of the legs and arms sufficient to spill water when holding a tumbler which was but three parts full.

During the following weeks he became rapidly worse. He was exceedingly restless and sleepless unless under the influence of sedatives. He continued to lose weight and became bed-ridden. Finally he developed difficulty in swallowing and was drowsy for a few days before his death on 18th December, 1935.

\section{Family History}

The accompanying diagram shows the family history as far as it can be ascertained. For the sake of convenience each member is numbered. The patient, L. T. J. E., is number 11.

His paternal grandfather (2) married twice, the first wife (1) being a first cousin. She died while still young and no abnormal features were noted. There were three sons and one daughter by this marriage. He afterwards married again, his second wife (3) living to the age of 90, and it is reported of her that she was always healthy. One daughter (8) resulted from this union. The grandfather (2) died at the age of 80 years. He is described as having been a clever, eccentric, and neurotic type, with insomnia. During the last two years of his life he developed twitching of the tongue and drooping of the eyelids. Unfortunately, no further information can be obtained, and it is not known if there was mental deterioration.

The four children of the first marriage are numbered (4), (5), (6), and (7). The eldest (4), a son, was a brilliant science student, who obtained a D.Sc. 
degree. He went to Australia and became a Government analyst. About the age of 56, he developed loss of memory and mental deterioration which continued until his death at the age of 60 . His letters to his relatives in this country showed well the extent and progress of his mental failure. There is no record of paralysis or spasticity. The second son (5) showed signs of mental

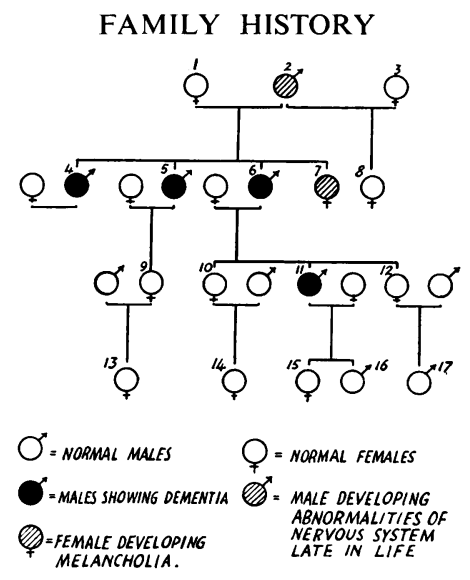

failure about the age of 63 years. He was admitted into Tooting Bec Mental Hospital in July 1922 at the age of 65 . We are indebted to Dr. F. M. Turnbull for allowing us to see the case notes; these showed that the patient, on admission, displayed considerable memory defect for recent events and was unable to think or speak coherently ; he was disorientated in time and place, and required assistance in dressing ; his habits were degraded. He gradually became more demented and died in April 1924, at the age of 67. There was no record of spasticity or paralysis. The third son (6) was the father of our patient. He was employed as an accountant in the same firm as that in which our patient subsequently held a post and was considered a trusted and gifted employee. At the age of 50 he began to show mental failure, and during the following two years this change became so pronounced that he was retired from active employment. For sentimental reasons he was allowed to remain in the office in an inferior position when he was long past usefulness. At the age of 53 he accidentally cut himself, developed septicæmia, and died. There is no record of difficulty in walking or speaking. The fourth sibling, a daughter (7), developed melancholia at the age of 45 years, and was admitted into Bethlem Royal Hospital in March 1902. We are indebted to Dr. J. G. Porter-Phillips for a description of this illness. It was the first attack, and when examined, she was in a state of severe depression and showed considerable anxiety. Although there was no retardation there was much inhibition of activity and she was unable to occupy herself in any way, except to talk about her misfortunes. She was actively suicidal and made one attempt to injure herself. She improved steadily and continuously until she was discharged "relieved" in February 1903. We are informed by the relatives that recovery was complete and she lived until about 65 years of age. She became very depressed again 
shortly before her death. There is no certain evidence of mental deterioration in this case.

The daughter (8) of the grandfather's second marriage lived to be more than 80 years of age, and no abnormal features are reported.

In the next generation (9), (10), and (12) are reported to be healthy subjects ; (11) is our patient.

In the following generation the children are too young to be expected to show any example of the disease. The children (15) and (16) of our patient are described as being sensitive, somewhat neurotic, and inclined to be depressive in temperament.

In brief, therefore, it would seem that of the four children of the first affected generation, the eldest developed an intense dementia, beginning at 56 and proving fatal at 60 . The second developed mental failure at the age of 63 and the illness progressed rapidly into a profound dementia with death from this cause at the age of 67 . The third exhibited mental deterioration at the age of 50 , but the progress of the disease was curtailed by a fatal septicæmia occurring two years later. These three were all males. The fourth sibling was a female who developed an involutional melancholia which resolved completely without mental deterioration, only to relapse again shortly before her death at the age of 65 .

\section{Post-mortem Examination}

An autopsy was performed at Peckham House Mental Hospital and the brain was preserved intact for future study. No abnormal finding was reported at post-mortem examination beyond some atheroma of the aorta.

Brain (after fixation).- The brain weighed $1,470 \mathrm{gm}$. On examination it was symmetrical and there was no suggestion of wasting of the convolutions, although there was slight thickening of the leptomeninges, particularly over the frontal lobes. On stripping off the pia-arachnoid, however, there was seen to be slight but very definite shrinkage of the convolutions of both frontal lobes. The basal vessels were normal in size and distribution, and they appeared to be free from atheroma. On horizontal serial sectioning, the white matter of the cerebral hemispheres was firm in consistency and without any foci of softening. The grey matter, both of the cortex and basal ganglia, appeared normal. The lateral ventricles showed a slight degree of dilatation and the choroid plexuses were cystic. The left cerebral hemisphere weighed 570 and the right $550 \mathrm{gm}$. The pons, cerebellum, and medulla appeared normal to naked eye examination.

Histology.--The histological findings in the brain are those which we normally associate with Alzheimer's disease, namely, extensive changes of a degenerative nature in the nerve cells and the presence of abundant senile plaques. The accompanying photographs demonstrate the intensity of the disease and the reactive processes at work.

The alterations are widespread in the cortical grey matter and are most marked, as is usual in Alzheimer's encephalopathy, in the cornu Ammonis and frontal cortex : in these areas the normal architecture has been destroyed, all 


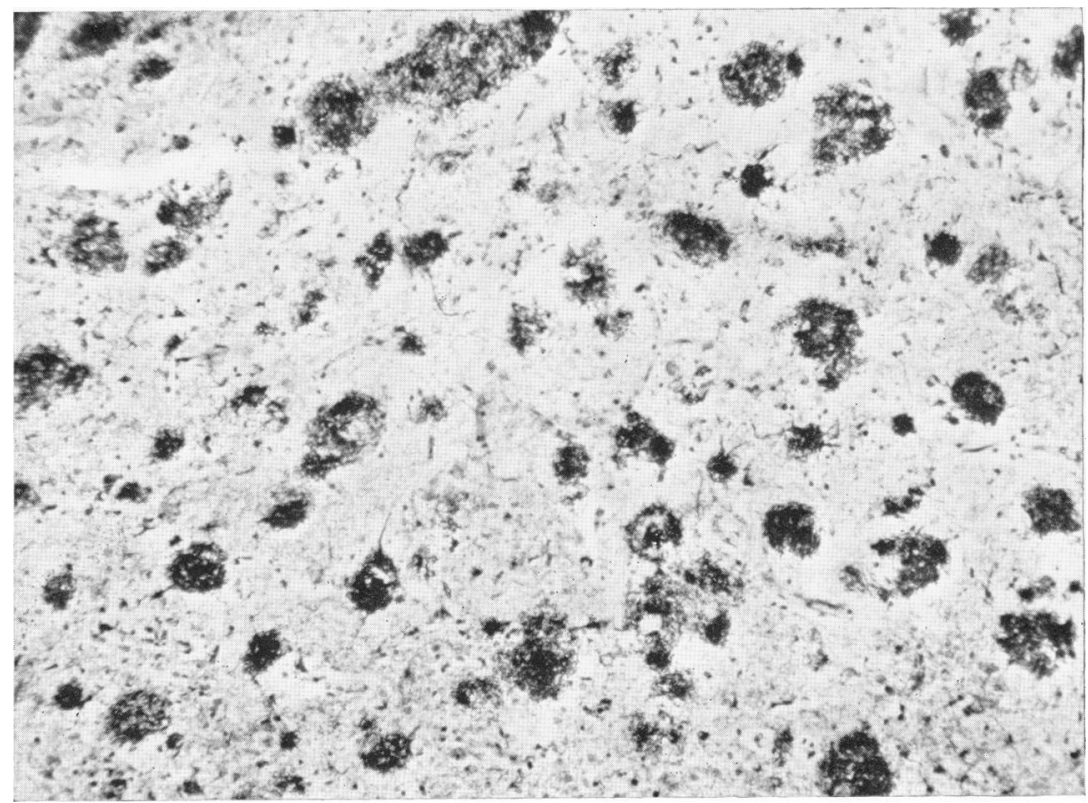

Fig. 1.-Frontal Cortex : showing abundance of senile plaques ; microglial processes can be distinguished projecting from some of these, especially the smaller of them. (Hortega's microglial method : low power.)

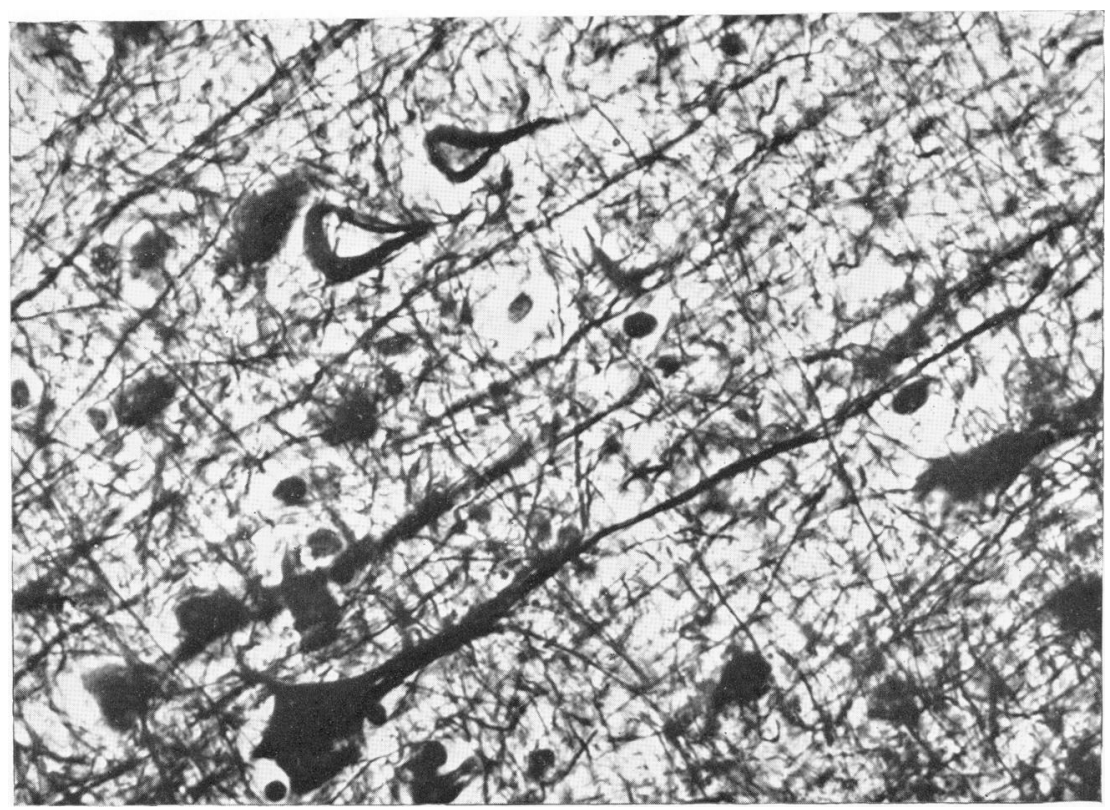

Fig. 2.-Frontal Cortex: showing neurofibrillary changes in the third layer. (Hortega's double impregnation ; high power.) 


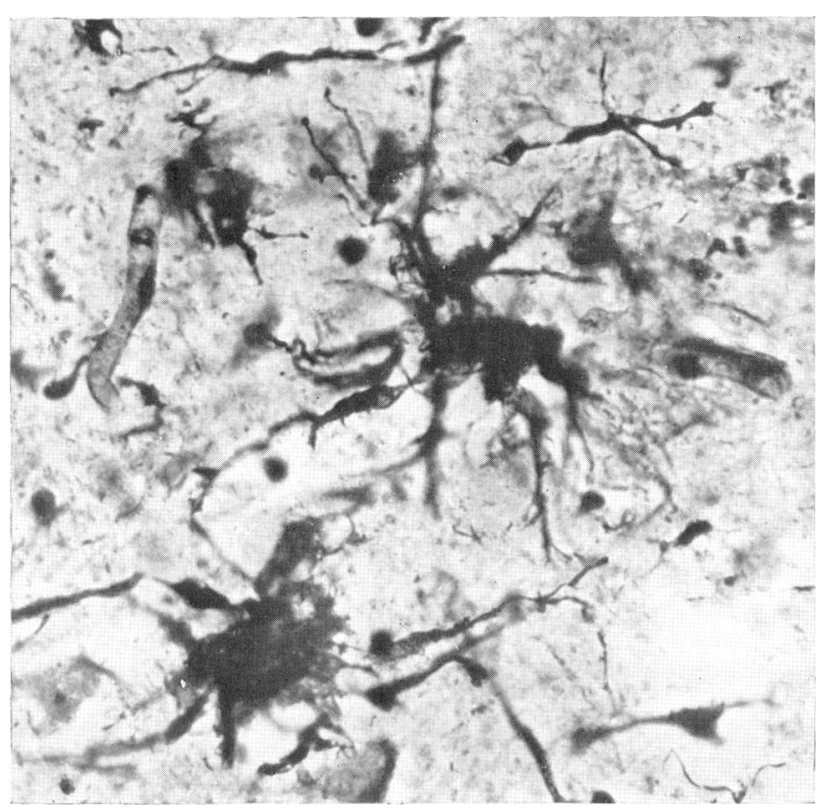

Fig. 3.-Cornu Ammonis : modified mesoglial elements are to be seen in the earliest stage of plaque formation. (Hortega's method for microglia : high power.)

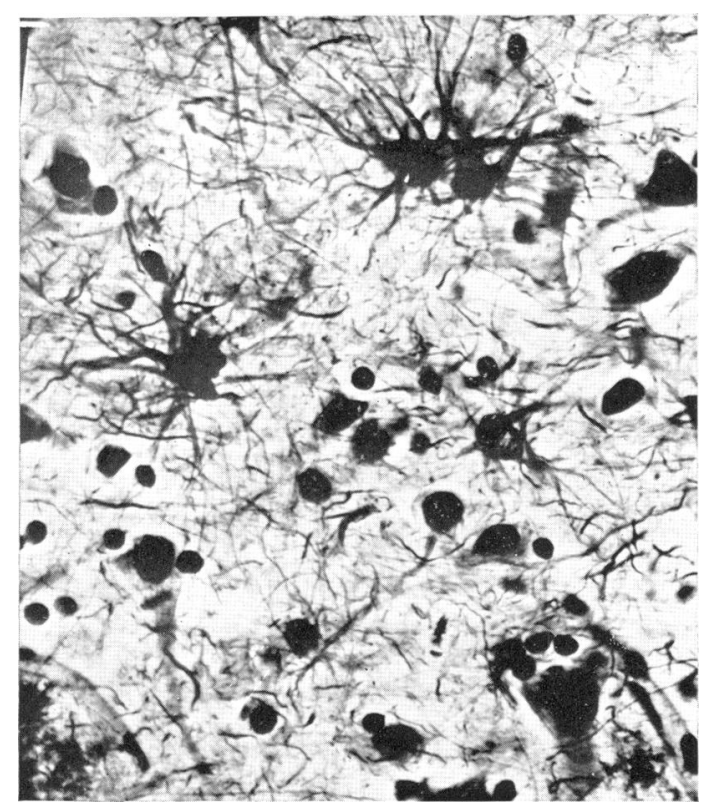

Fig. 4.-Frontal Cortex : reactive gliosis in an area of extreme neuronal degeneration. The astrocytes are of the fibrous type and one of them has just undergone fission. (Hortega's silver carbonate method for astroglia : high power.) 


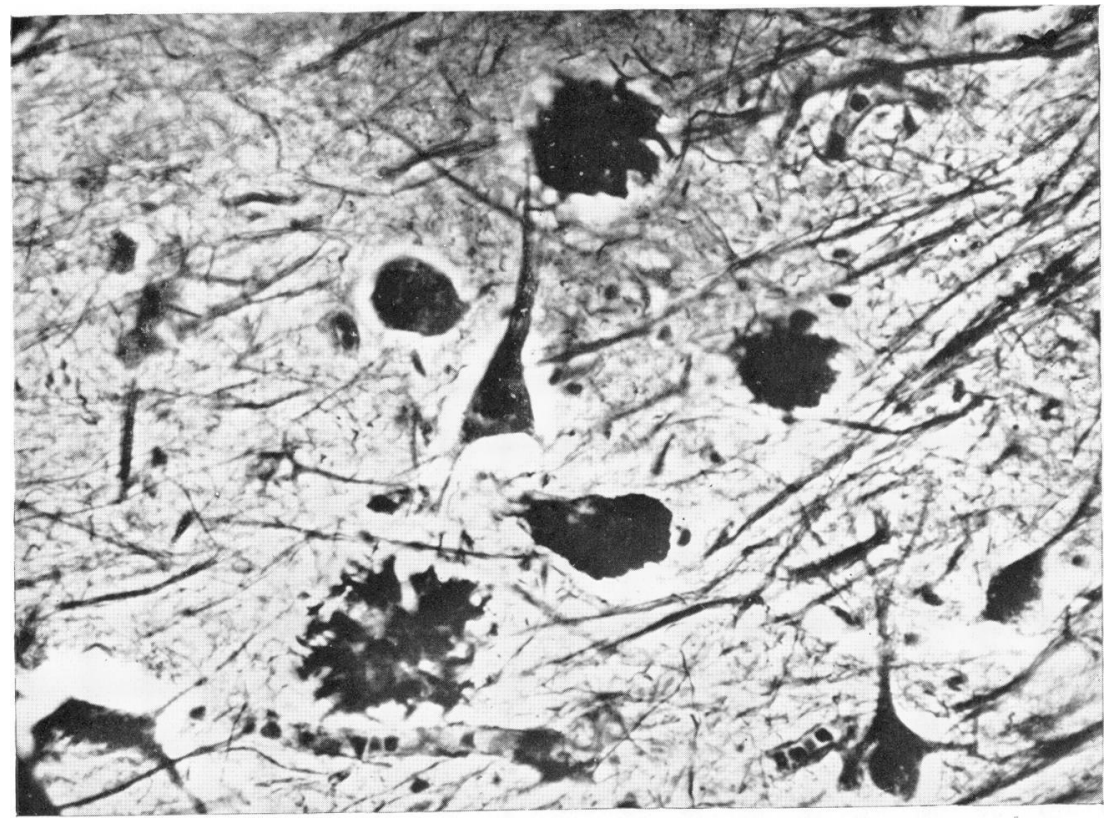

Fig. 5.-Fascia Dentata : three small senile plaques can be seen in close proximity to atrophying nerve cells. (Bielschowsky-da Fano silver impregnation; high power.)

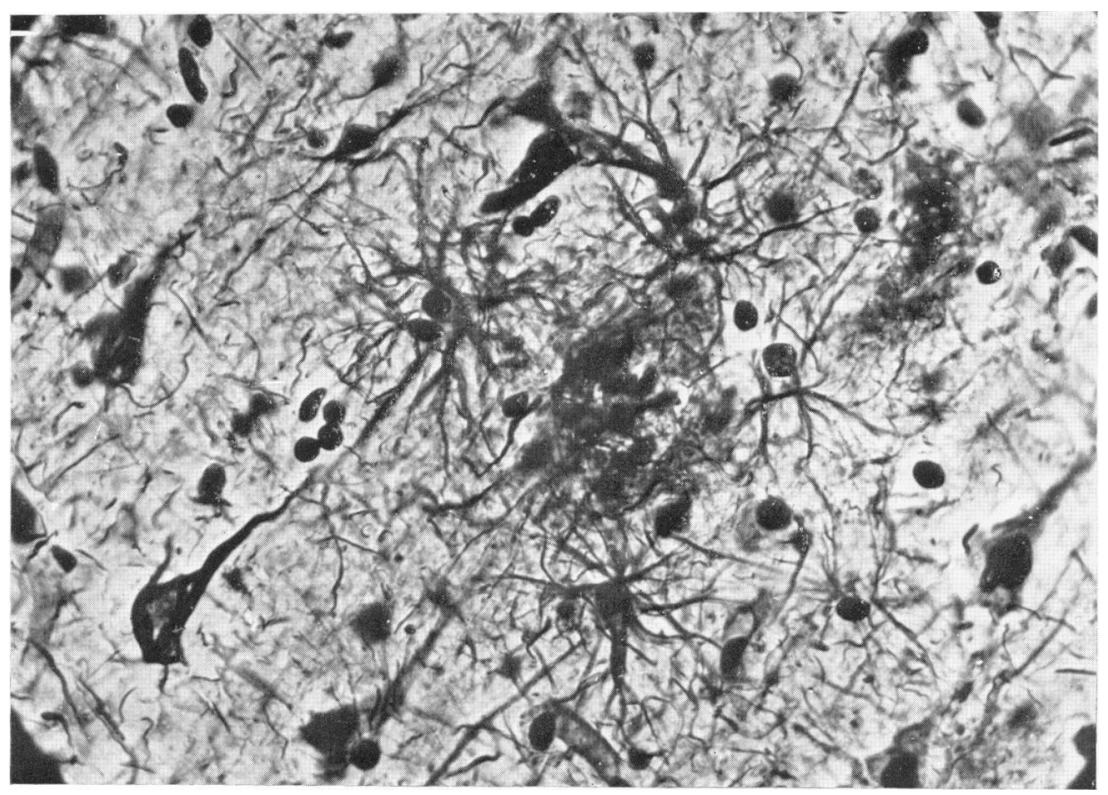

Fig. 6.-Frontal Cortex : showing condensation of fibrous astroglia around a plaque which shows in its centre modified mesoglial elements. Note neurofibrillary alterations. (Hortega`s silver carbonate method for astroglia ; high power.) 
layers being affected; nerve cells are reduced in number and what remain are atrophied or show nuclear alterations and neurofibrillary changes in the form of well-marked "loops" and " tangles." Microglial elements, often extremely modified, can be seen in relation to the plaques and also to some of the atrophied nerve cells. The astroglia is increased in amount, particularly in the superficial and subcortical white matter, and is of the fibrous variety. The cerebral capillaries show only a little thickening and practically no pericapillary fibrosis. The leptomeninges over the frontal poles reveal chronic fibrous thickening. Plaques were not found in the basal ganglia, mid brain, pons, or medulla. The choroid plexus showed no abnormality other than the presence of some corpora amylacia.

\section{Commentary}

In the family described by Lowenberg and Waggoner, four out of five siblings and their father were affected, succumbing at the ages of $34,37,35,36$, and 33 respectively; the fifth sibling had met with a violent death and there was no record of any mental abnormality. In each case the illness appears to have been more or less identical, although the duration varied from 2 to 6 years. The brain of the youngest of the four siblings, whose illness lasted 6 years, was studied carefully by these authors, and the findings were typically those of Alzheimer's disease with its extensive degeneration of cortical neurones and the presence of numerous plaques; an authoritative description of the naked eye findings of the brain of the third sibling, which the authors read, suggests that the histology would have proved similar to that of their patient. It is interesting to note that the parents of the father were first cousins, as in the case of our patient.

The individual pathological features of Alzheimer's disease are known to occur in other disease processes, but the association of widespread neurofibrillary alterations and a superabundance of senile plaques is highly characteristic of this presenile dementia.

Nevertheless, Jervis and Soltz (1936) have maintained that an adequate morbid histology of this disease in the absence of a typical clinical picture is insufficient evidence for establishing the diagnosis. Without attempting to challenge these criteria of diagnosis and without venturing into a discussion on the subject of possible variations in the clinical picture, we consider that the clinical findings in our patient are compatible with the suggested diagnosis, and the widespread cortical changes are in keeping with the extreme intellectual impairment and destruction of personality which were the essential features of this case from the inception of the illness. With regard to the three male members of the previous generation, we are on less certain ground, as the histories available are inadequate. The fact remains, however, that each one of them presented symptoms of ingravescent disturbance of cortical function which would be consistent with the relentless progress of a widespread and slowly developing destruction of cortical neurones. If we disregard for the moment the case of the third sibling who, after the disease had progressed for 
two years, met with a fatal accident possibly the direct result of his oncoming dementia, we still have two members of this generation who suffered from a progressive dementia which proved fatal in four years. It may be argued that the second of these is unlikely to be a presenile dementia because the age of onset was 63 , and the presenium is generally regarded as ceasing at the age of 60. Some authors, however, allow the presenium to extend to the age of 65 . We feel that there cannot be any arbitrary age limit between the presenium and senium, because the rate of ageing varies so considerably in different families and individuals. Also, there is more than a difference in age onset between Alzheimer's disease and senile dementia; it is a question of degree. The dementia in the latter is seldom so profound as is usual in the former disease, a fact which is in keeping with the difference in the extent of degeneration of cortical neurones. Moreover, the symptomatology of senile dementia is seldom so widespread in its first years as in Alzheimer's disease and death is less often the result of the decorticating process than of some intercurrent illness. In the case of the second sibling, the disease so resembles that of the eldest brother that there can be no doubt that the underlying cause was the same. If the Alzheimer's symptomatology be regarded as a reaction by disturbance of personality and impairment of intellect to a pathological process in the brain tantamount to abnormal ageing and possibly due to intrinsic (e.g. abiotrophic) or extrinsic factors, then the later age of onset in this second member of the family would suggest a greater individual resistance to this familial weakness.

\section{Summary}

1. A case of Alzheimer's disease is described, the clinical and histological findings being typical.

2. Perusal of the family history reveals the fact that three out of four siblings of the previous generation, including the father of our patient, suffered from a presenile dementia, which in all probability, was identical with that of our patient.

3. As in the case of familial Alzheimer's disease, described by Lowenberg and Waggoner, the parents of the first affected generation were cousins.

We wish to express our thanks to Dr. F. R. King, Medical Superintendent of Peckham House, for permission to publish the case, to Dr. A. O'Neill, Medical Superintendent of Napsbury Hospital, and to Professor Hugh Cairns for the interest they have taken and for laboratory facilities granted for this study, also to Dr. P. del Rio Hortega for his unfailing kindness and help in the preparation of the histological sections and photomicrographs.

\section{REFERENCES}

Gillespie, R. D., et al. (1933). Proc. roy. Soc. Med., 26, 1,080.

Jervis, G. A., and Soltz, S. E. (1936). Amer. J. Psychiat., 93, 39.

Lowenberg, K., and Waggoner, R. W. (1934). Arch. Neurol. Psychiat., Chicago, 31, 737.

Malamud, W., and Lowenberg, K. (1929). Ibid., 21, 805.

Mayer-Gross, W. (1938). Proc. roy. Soc. Med., 31, $1,446$.

Rothschild, D. (1937). Amer. J. Psychol., 93, 757. 